\title{
MASJID DALAM PELESTARIAN SENI BANGUNAN ISLAM DI MESIR
}

\author{
Nur Arfiyah Febriani \\ Sekolah Tinggi Agama Islam (STAI) At-Taqwa Rawa Lumbu Bekasi \\ Email: royyana12@yahoo.com.
}

Abstrak: Salah satu efek ibadah adalah kebudayaan, dan kebudayaan tidak terlepas dari ibadah. Demikian dengan masjid dan seni. Dari masjid, lahir berbagai macam budaya yang melahirkan seni yang menyenangkan dan bermanfaat bagi kehidupan setiap orang yang bertandang kepadanya. Masjid, dalam sejarah pendiriannya dan proses yang dilalui mengalami kemajuan yang pesat, baik dari struktur bangunan dan fungsi yang semakin dikembangkan. Berangkat dari tempat yang menjadi pusat kegiatan masyarakat Mesir ini, memungkinkan masjid menjadi fasilitator dinamika seni dan budaya, politik, ekonomi dan pendidikan masyarakat setempat, yang pada akhirnya melahirkan sebuah universitas Islam tertua, ternama dan terbesar di dunia, al-Azhar.

Kata Kunci: al-Azhar, Masjid, Arsitektur, Seni dalam Islam.

\section{A. Pendahuluan}

Herbert Read merumuskan definisi seni dengan ungkapan: "art is most simply," seni secara sederhana sekali dan biasa sekali dapat didefinisikan sebagai usaha menciptakan bentuk-bentuk yang menyenangkan. Dalam budaya Islam, seni saja tidak cukup, tapi harus mengandung unsur etika. Hubungan antara yang indah dan baik ini bermakna hubungan seni dan etik (Gazalba, 1989: 1989: 223). Hubungan ini di antaranya dapat dilihat dalam ayat al-Qur'an:

Sesungguhnya kami Telah menjadikan apa yang di bumi sebagai perhiasan baginya, agar kami menguji mereka siapakah di antara mereka yang terbaik perbuatannya. (Q.S. al-Kahfi [18]: 7).

Harta dan anak-anak adalah perhiasan kehidupan dunia tetapi amalan-amalan yang kekal lagi saleh adalah lebih baik pahalanya di sisi Tuhanmu serta lebih baik untuk menjadi harapan. (Q.S. al-Kahfi [18]: 46).

Dari kedua ayat di atas, kita dapat mengetahui bahwa Islam sangat dekat dengan seni bangunan yang dapat melahirkan kesenangan bagi seseorang, 
dengan catatan semua harus dilandasi dengan iman dan taqwa manusia kepada Allah. Ini agar seni bangunan yang tercipta dalam kreativitas umat Islam, tidak keluar dari fitrahnya untuk dapat memberikan kebahagiaan hakiki bagi pribadi dan masyarakat umum, tanpa mudarat dan mengundang kemaksiatan. Sebagimana seorang ilmuan muslim bernama al-Farabi yang menjelaskan bahwa seni sebagai ciptaan yang berbentuk keindahan. Al-Ghazali mengatakan seni bangunan adalah kerja berkaitan dengan rasa jiwa manusia yang sesuai dengan fitrah.

Dari sini dapat diketahui bahwa karya seni bangunan dalam Islam memiliki cakupan yang sangat luas, maka dalam tulisan ini penulis hanya membatasi pada kajian seni bangunan masjid di Mesir. Tulisan ini juga akan dilengkapi beberapa masjid di seputar Mesir sebagai bahan perbandingan yang akan memperkaya kajian tentang seni bangunan Arab di Mesir.

\section{B. Masjid dan Seni}

Menurut Sidi Gazalba (1989: 239), masjid identik dengan seni. Ini karena banyak seni keindahan nan beretika lahir dari masjid. Sebut saja seni bangunan masjid. Bahkan bukan hanya dari segi bangunan secara fisik, bagi para jama' ah yang hendak mendatangi masjid juga harus memperhatikan kerapihan dan keindahan penampilan fisik dan memakai pakaian bagus, menjaga kebersihan sampai memakai wewangian. Ini adalah salah satu pengaruh positif dari salah satu sunnah dan perintah nabi bagi para umatnya. Oleh sebab itu, dalam Islam seni harus karena Allah, dilahirkan oleh sifat taqwa, dan hasilnya harus memberi efek positif untuk pribadi dan masyarakat (Gazalba, 1989: 230).

Setiap negara pasti memiliki ciri khas masing-masing dalam seni bangungan masjidnya. Satu hal yang sama, adalah tujuan dibangunnya masjid dengan arsitektur yang indah adalah untuk menampilkan karya seni yang dapat dinikmati oleh siapa saja yang datang melihatnya. Seni bahkan mengandung filosofi kehidupan, sehingga seni menunjukkan identitas suatu budaya dimana seni itu dibuat. Seni bukan hanya sekedar keindahan, ada nilai budaya yang disematkan pada setiap goresan yang ditoreh di atasnya.

Seni bangunan di negara-negara Arab yang terkenal indah dan megah tidak dipungkiri menjadi kiblat pembangunan masjid di seluruh dunia. Keindahan arsitektur dari bangunan di negara-negara Arab ini, bahkan mengilhami seorang seniman non muslim untuk memperkaya pengetahuan tentang desain bangunan dan membuatnya jatuh cinta dengan Islam, sampai akhirnya ia memut uskan untuk masuk Islam. 
Masjid bukan hanya sarana untuk menjalankan ritual ibadah, lewat kreativitas para arsitektur bangunan muslim, tempat ini juga dapat menjadi sarana mempelajari sejarah seni dan budaya suatu bangsa. Hal ini sangat beralasan karena: "Kesenian bukan berada di luar kehidupan Islam, sedang masjid adalah pusat dari kehidupan itu sendiri” (Gazalba, 1989: 239). Jadi bisa disimpulkan, sebagai pusat kehidupan yang dapat mengakomodir segala bentuk kebutuhan dan aktivitas sosial, masjid dapat menjadi salah satu identitas suatu masyarakat dimana masjid itu dibangun.

\section{Arsitektur Masjid di Mesir}

Bisa jadi kebanyakan dari kita tidak tahu bahwa Rasulullah saw ternyata adalah juga seorang arsitek (Ahmad Y al-Hassan dan Ronald R. Hill, 1993: 292293). Ini terbukti dari rancangan mayoritas masjid di timur tengah yang menduplikat gaya seni arsitektur masjid yang pernah Nabi buat.

Masjid pertama yang didirikan oleh Nabi Muhammad saw, adalah masjid Quba yang didirikan pada tahun pertama Hijrah (622 M). Masjid ini dibangun oleh Nabi sendiri, bergotong royong dengan para sahabat. Masjid Quba sangat sederhana sekali, dibuat dari pelepah dan daun korma serta batu-batu gurun. Mihrab yang menjadi tanda arah kiblat dibuat dari batu bata. Masjid memiliki ruang persegi empat dengan dinding disekelilingnya. Di sebelah utara dibuat serambi untuk shalat, bertiang pohon korma bercampur tanah liat. Begitu juga kira-kira pembuatan serambi pada keliling dinding masjid. Di tengah masjid terdapat lapangan terbuka yang terdapat tempat mengambil air wudu. Arsitektur mesjid ini menjadi inspirasi bangunan masjid yang dibangun sesudahnya bahkan sampai saat ini, tidak terkecuali masjid- masjid di Mesir (Gazalba, 1989: 297).

Jika dibayangkan, masjid rancangan Nabi saat itu masih sangat sederhana. Hal ini sangat wajar, karena pada masa itu masjid Quba adalah sebagai masjid yang pertama dibuat, yang diutamakan adalah fungsi masjid sebagai tempat untuk shalat Nabi dan para sahabat. Setelah fungsi utama ini dapat tercapai, baru kemudian beberapa masjid yang dibangun kemudian mulai ditingkatkan kualitasnya, baik dari segi arsitektur, bahan pembuatan, sampai pengembangan fungsinya.

Seiring perkembangan zaman, masjid semakin memberikan kontribusi unt uk masyarakat. Untuk merespon kebutuhan dan kebudayaan masyarakat yang semakin berkembang, maka baik dari segi arsitektur, fasilitas dan fungsi masjid juga semakin dikembangkan. Masjid Quba yang pernah Nabi bangun di 
Madinah, pada saat ini sudah mengalami renofasi bangunan, dan tampilannya saat ini sudah seperti kebanyakan masjid berarsitektur modern lainnya.

Untuk masjid di negara Mesir, juga mengambil arsitektur dari bangunan masjid Quba. Potret dari beberapa masjid yang pernah penulis sempat kunjungi ketika melakukan riset disertasi di sana dapat dilihat pada gambar berikut:

\section{Masjid al-Azhar}

Sebagaimana diungkapkan, masjid al-Azhar didirikan setahun setelah pembukaan Mesir dan peresmian Kairo (Al-Qāhirah) sebagai ibukota negara (dinasti Fatimiyah). Pembangunan al-Azhar ini dimulai tahun 359 H/ $970 \mathrm{M}$ dan selesai pada tahun $361 \mathrm{H} / 972 \mathrm{M}$.

Menariknya, menara-menara yang terdapat dalam masjid ini tidak seluruhnya dibangun secara bersamaan. Akan tetapi tergantung kepada dinasti yang berkuasa pada masa itu. Artinya setiap dinasti memiliki menara sebagai sebuah kontribusi bagi masjid ini. Oleh sebab itu, menara di masjid ini akan bertambah, sesuai dinasti yang berkuasa pada masa itu dan kesepakatan yang disetujui oleh pihak dari al-Azhar.

Terlihat pintu-pintu yang di dalamnya digunakan sebagai ruang yang berfungsi sebagai ruang belajar (Ahmad Y al-Hassan dan Ronald R. Hill, 1993: 39-41). Namun, jika jumlah pelajar melebihi kapasitas ruangan, maka ruangan tempat shalat bahkan halaman tengah masjid juga dapat berfungsi sebagai tempat belajar. Fungsi masjid untuk para pelajar menimba ilmu dapat dilihat pada gambar berikut:

Gambar II: Para pelajar sedang belajar di ruang shalat dalam masjid al-Azhar

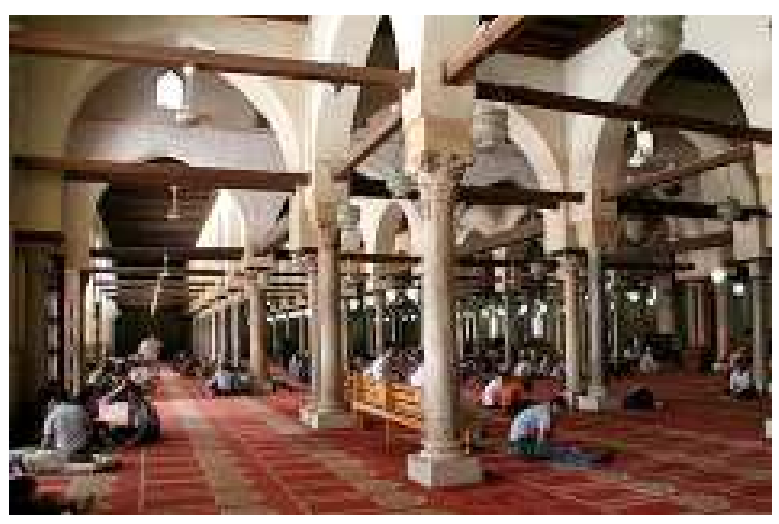

Para pelajar dalam gambar di atas, terlihat asyik dan khusuk dalam belajar dan menghafal. Dalam gambar ini, ruangan shalat dipenuhi oleh para pelajar yang sedang belajar. Jika waktu shalat telah masuk, maka para pelajar akan segera melaksanakan shalat berjama'ah. Jika kapasitas ruangan tidak memadai, maka baik ibadah shalat maupun aktivitas belajar akan menggunakan lapangan yang berada di tengah masjid. 
Masjid al-Azhar tidak dihiasi berbagai corak kaligrafi dengan cat warna warni yang bertuliskan ayat-ayat al-Qur' an sebagaimana masjid kebanyakan di Indonesia, namun masjid ini dihiasi dengan kaligrafi ayat al-Qur'an yang terbuat dari batu yang dipahat. Tradisi seni bangunan arab denga batu berhias ini disebut dengan ashlar masonry. Kelebihan batu sebagai bahan bangunan di Mesir dan berbagai negara Timur Tengah lainnya, karena batu yang bernama batu gamping ini sangat tahan terhadap berbagai macam cuaca dan memberikan warna gading yang indah ketika terkena cahaya (Ahmad Y alHassan dan Ronald R. Hill, 1993: 101). Menurut penulis, warna batu ini menjadikan masjid al-Azhar dan berbagai masjid di Mesir terkesan eksotik. Masjid ini juga dihiasi oleh ratusan tiang penyanggah dan beberapa aksesoris bangunan masjid yang membuat masjid ini terkesan elegan.

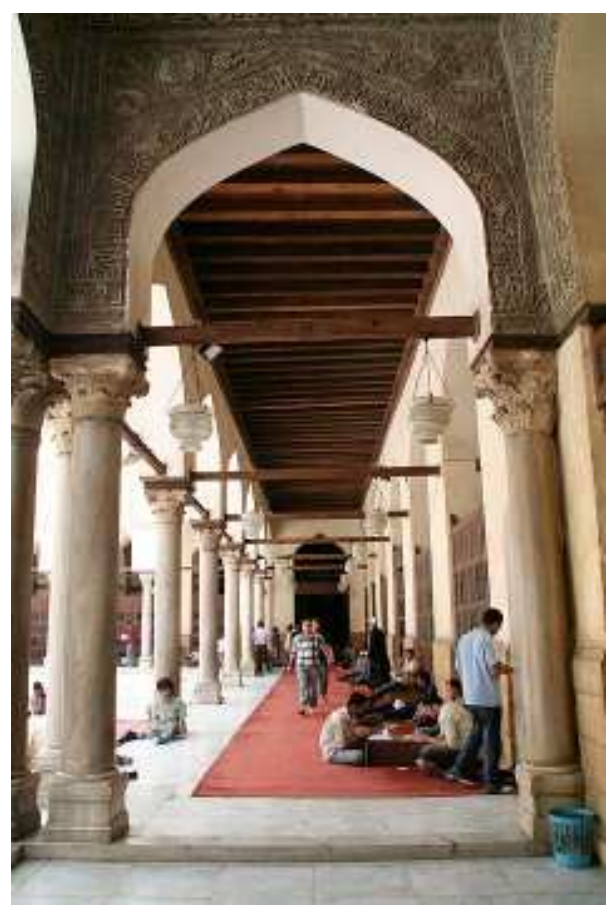

Gambar III: Kaligrafi ayat-ayat al-Qur'an berbahan dasar batu yang dipahat pada lorong-lorong masjid

Bukan hanya gaya arsitekturnya yang banyak diikuti oleh pembangunan masjid di seluruh dunia, bahkan kegiatan ilmiah yang pada akhirnya berkembang menjadi sebuah universitas tertua di dunia ini menjadi sumber inspirasi universitas-universitas lain di dunia, tidak terkecuali universitas Oxford. Oxford didirikan dua abad setelah al-Azhar, sistem dan tradisinya juga sama seperti al-Azhar. Bahkan buku-bukunya adalah terjemahan dari karangankarangan ulama al-Azhar, setelah pasukan perang salib kembali ke timur tengah, mereka mendapat dua tradisi dari timur tengah, yaitu: mandi dan keilmuan (Keluarga Mahasiswa Banten, 2010: 182-183). Budaya bersih dan gaya hidup sehat juga salah satu ajaran yang sangat ditekankan dalam Islam. Tidak kalah penting tent unya, dengan kewajiban memburu ilmu pengetahuan.

\section{Masjid 'Amru Ibn 'Ash}

Para pengunjung dari berbagai penjuru dunia, tidak melewati tour ke salah satu masjid bersejarah yang satu ini. Masjid 'Amru Ibn 'Ash juga berfungsi 
sebagai pusat berbagai kegiatan sosial sebagai mana masjid al-Azhar. Mesjid ini terletak di daerah Fusthat atau disebut juga daerah Mishr el Qadima (Old Egypt/ ibukota Mesir yang lama). Mesjid 'Amru Ibn 'Ash merupakan masjid pertama yang dibangun di Mesir (wilayah Afrika). Mesjid ini dibangun oleh 'Amru Ibn 'Ash pada tahun $21 \mathrm{H} / 642 \mathrm{M}$, at as perintah Khalifah Umar bin Khaththab, setelah penaklukan Mesir oleh Islam. Masjid ini dibangun setelah membangun ibukota Mesir, ibu kota Fusthat.

Dengan terdapatnya tempat wudu pada ruang tengahnya, masjid ini mengikuti arsitektur masjid Quba yang pernah dibangun Nabi. Fungsi tempat wudu pada masjid yang mengikuti arsitektur bangunan masjid Nabi ini, memiliki peran yang sangat besar bagi jama'ah yang batal dalam wudu. Dapat dibayangkan, jika seseorang ada yang batal dalam wudunya, sedang masjid dipenuhi ribuan orang, pasti akan sangat sulit untuk mengambil air wudu di toilet dan tempat wudu yang berada di luar masjid. Tapi dengan adanya tempat berwudu ini, baik jama' ah yang berada di depan, tengah dan belakang ruangan masjid, akan dengan mudah kembali berwudu, sungguh praktis dan sistematis.

Salah satu keistimewaan pada masjid ini dapat terlihat dalam tradisi bulan Ramadhan di Mesir, di mana umat Islam biasa melaksanakan i'tikaf di 10 hari terakhir di bulan Ramadhan. Syaikh Jibril seorang Imam yang do'a witirnya sangat panjang dan memiliki makna sungguh dalam mengenai relasi tuhan dan manusia, menjadi salah satu daya tarik ribuan jama'ah untuk memutuskan i'tikaf di masjid ini. Pada gambar berikut, terlihat ribuan jama'ah melaksanakan salat tarawih di masjid 'Amru Ibn 'Ash. Tampak ruang tengah masjid yang kosong, dan tempat wudu yang berada di lapangan di tengah masjid yang penulis bahas di depan, keseluruhan ruangan masjid dipenuhi jama'ah bahkan sampai ke jalan raya. Pada saat melaksanakan salat tarawih ini, akses jalan umum ditutup beberapa kilometer untuk menampung ribuan jama'ah.

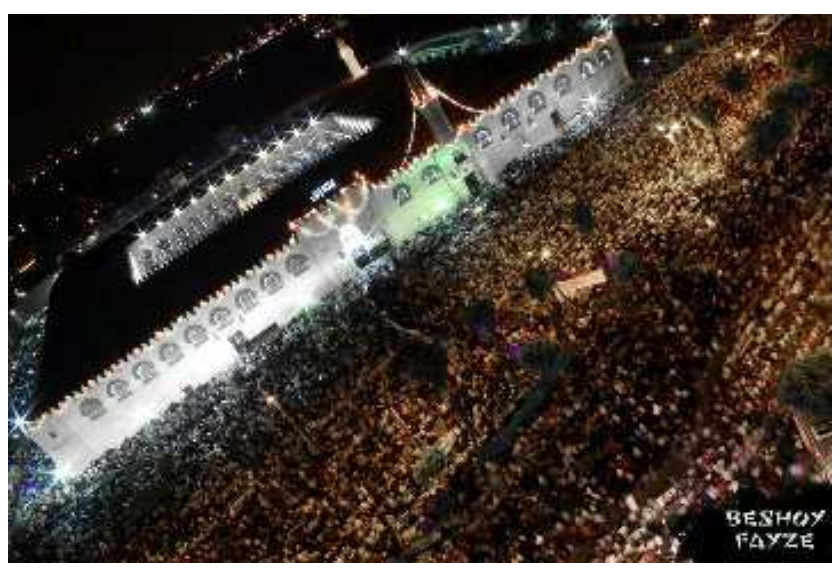

Gambar VI: Suasana shalat tarawih dan i'tikaf di masjid 'Amru Ibn 'Ash. 


\section{Masjid Muhammad Ali Pasha}

Masjid bergaya arsitektur Turki ini berada di dalam benteng Qaitbay (Qaitbay Citadel). Dibangun antara tahun 1830 sampai dengan 1848 Masehi. Arsiteknya adalah Yusuf Bushnak dari Istanbul, Turki. Bangunan masjid yang menjulang terlihat sangat indah karena letaknya yang berada di ketinggian. Penulis juga sempat mengabadikan pemandangan kota kairo dari halaman masjid ini, berikut foto kota Mesir yang dapat dinikmati dari halaman masjid Muhammad Ali Pasha.

Posisi masjid yang berada di atas bukit, memungkinkan para peziarah memandang kota Kairo. Tidak heran jika posisi strategis ini juga yang menjadi pertimbangan Solahudin al-Ayyubi unt uk membangun bentengnya yang monumental di wilayah ini. Bahkan, benteng pertahanan (benteng Qaitbay/ Qaitbay Citadel) yang dibangun oleh Solahudin al-Ayyubi tersebut, pada saat ini sudah menjadi musium yang mengabadikan sejarah perjuangan Mesir dan kemerdekaannya. Sedangkan dibelakang penulis, adalah masjid kembar atau masjid Sultan Hasan dan Masjid Rifa'i yang akan dibahas selanjutnya. Besarnya bangunan kedua masjid tersebut, memungkinkan peziarah dapat melihatnya meskipun dari jarak yang sangat jauh.

Kemegahan lain dari masjid Muhammad Ali Pasha ini dapat dilihat dari ruang utama tempat shalat. Lampu hias nan megah menyambut kedatangan para peziarah. Sayangnya, kubah masjid ini tidak dapat penulis abadikan dengan kamera digital penulis. Karena ruangan yang diseting redup dan kubahnya yang sangat besar sehingga tidak cukup tertangkap lensa kamera. Seni pahat pada dinding batu menjadi salah satu saksi kebudayaan Islam pada saat masjid ini dibangun. Mengingat Mesir adalah daerah bergunung batu dan padang pasir, maka kebanyakan bahan bangunan dinding dan lantainya adalah berbahan dasar batu dari gunung yang mereka pahat. Luar biasanya, lokasi pembangunan benteng dan masjid inipun terletak diatas bukit yang mereka pahat sehingga dapat didirikan benteng di atasnya. Oleh sebab itu, benteng Solahudin terkenal sulit ditembus oleh para musuhnya (Hamka, 2002: 334-335).

\section{Masjid Sultan Hasan}

Masjid dengan arsitektur menawan ini terletak di belakang benteng Qaitbay (Qaitbay Citadel). Meski usianya sudah ratusan tahun namun kekokohan bangunan terlihat sangat jelas. Dahulu bangunan masjid ini berfungsi juga sebagai madrasah (sekolah). Masjid ini dibangun oleh Sultan al-Nashir Hasan bin Muhammad al-Qalawun pada tahun 757 H/1421 M, penguasa dinasti Mamluk Bahriyah yang menguasai Mesir waktu itu. 
Masjid ini merupakan masjid termahal yang dibangun di wilayah Mesir, yang menghabiskan dana sekitar 100 ribu dinar waktu itu. Mesjid ini mempunyai dinding yang tinggi, dan pintu masuknya merupakan yang tertinggi dari mesjid-mesjid yang ada diwilayah Mesir. Bahkan karena besarnya masjid ini, penulis kesulitan mencari titik agar dapat mengabadikan gambar masjid ini.

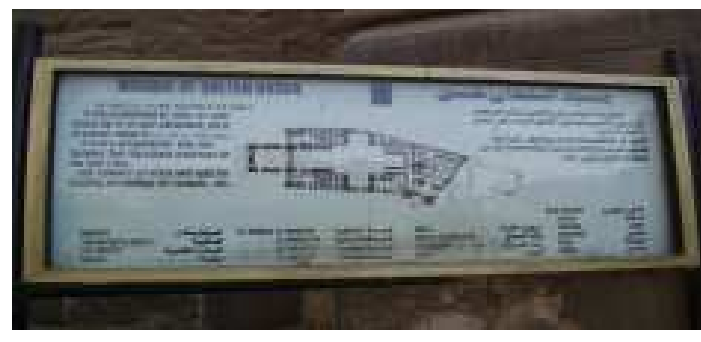

Gambar X: Denah masjid berikut segenap fasilitas yang terdapat di dalamnya

Dalam denah ini dinyatakan bahwa masjid ini pada saat dibangun adalah masjid terbesar di dunia. Menariknya, masjid ini juga memiliki fasilitas rumah sakit, asrama bagi para guru dan murid, ruang khusus yang menyediakan kebutuhan pelajar mengenai pemikiran dari 4 aliran mazhab yang terkenal, dan lain-

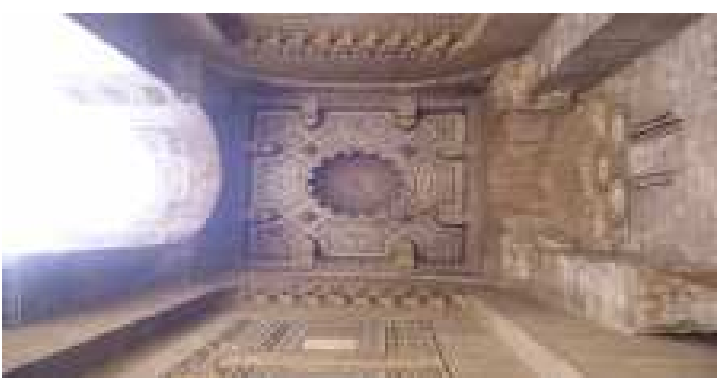
lain.

Gambar XII: Salah satu tiang penyanggah kubah masjid

Selain kemegahan masjid, penulis juga sempat mengabadikan beberapa ruang yang dipakai oleh para pelajar berdasarkan ruangan yang berisi tentang buku atau pemikiran-pemikiran dari imam Hanafi, Maliki, Syafi'iy, dan Hanbali. Dalam ruangan-ruangan ini diajarkan pemikiran para tokoh dari keempat aliran mazhab ini, sesuai dengan ruangan kelas dari tokoh yang dipilih para pelajar.

\section{Masjid Ar-Rifa'i}

Masjid ini dibangun dalam 2 tahap yaitu pada kurun waktu tahun 1869 dan 1912. Letaknya berhadapan dengan masjid Sultan Hassan. Arsiteknya adalah Husayn Fahmi Pasha yang merupakan sepupu jauh dari Mohammad Ali Pasha.

Masjid Sultan Hasan dan masjid Rifa'i dikenal juga dengan sebutan masjid kembar, karena struktur bangunan dan arsitekturnya yang memiliki kemiripan. Di dalam masjid Rifa'i ini juga terdapat makam dari Muhammad Reza Fahlefi, seorang raja Iran yang digulingkan dan terusir dari Iran pada tahun 1979, yang mendapat suaka di Mesir. Makam ini memiliki ruangan khusus di dalam masjid, 
berlantaikan marmer hijau yang secara khusus juga dipesan untuk pembangunan makam ini. Dikatakan khusus, karena keseluruhan lantai pada bangunan masjid ini berbahan batu alam biasa dan berwarna kecoklatan yang ditutupi dengan karpet, yang berbeda hanya warna marmer makam sang raja. Bahkan makam sang raja, tidak luput dari kreativitas para seniman pengukir batu di Mesir. Di atas batu marmer berwarna hijau itu, terukir nama sang raja dan lambang negara.

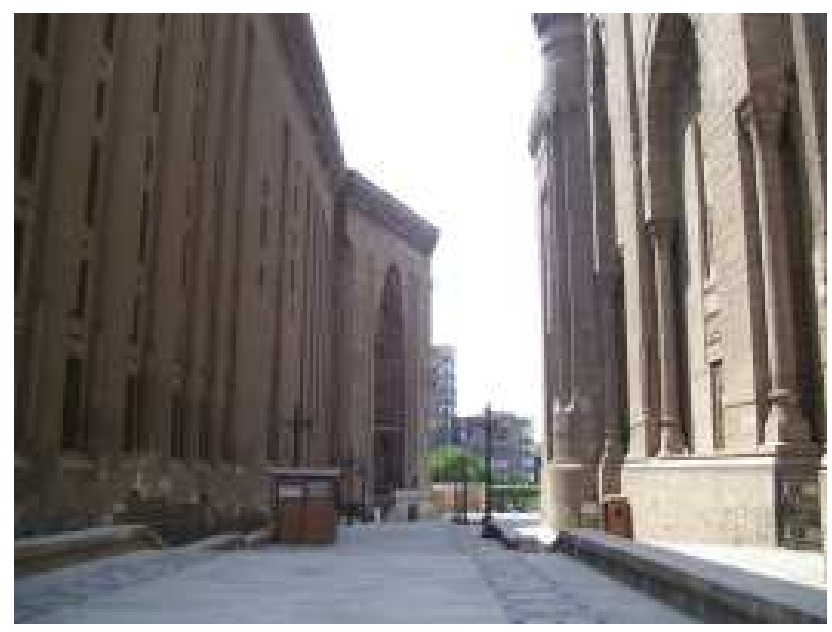

Gambar XIX: Masjid Sultan Hasan (kiri) dan Masjid Rifa'i (kanan)

Dalam kaitan ini, dapat diketahui seni arsitektur pada beberapa bangunan masjid di daerah Mesir adalah kesan indah, mewah dan bersahaja dapat ditangkap dari gambar-gambar di atas. Dengan berbagai fasilitas ini, tidak heran jika masjid-masjid ini memiliki multifungsi, tergant ung pada kebutuhan masyarakat sekitar. Masjid benar-benar menjadi pusat kehidupan orang-orang di Mesir. Oleh sebab itu masjid-masjid yang berada di daerah Mesir menjadi pusat perhatian pula para peziarah dari seluruh dunia yang datang ke sana. Arsitektur masjid di Mesir juga mengilhami gaya arsitektur pada masjid-masjid lain di seluruh dunia, termasuk di Indonesia.

\section{Simpulan}

Masjid tidak dapat dipisahkan dalam kehidupan seorang muslim, karena masjid memang menjadi pusat kehidupan umat Islam. Potensi besar masjid sebagai pusat kegiatan masyarakat, memberikan kontribusi yang sangat positif pada peningkatan kualitas dakwah, seni dan budaya, sosial, politik, ekonomi bahkan pendidikan. Di Mesir, masjid mengakomodir berbagai kegiatan sosial masyarakat terutama pada aktivitas pendidikan, pada akhirnya dapat melahirkan sebuah universitas al-Azhar, sebagai universitas Islam tertua dan terbesar di dunia. 


\section{Daftar Pustaka}

Asrohah, Hanun. 1999. Sejarah Pendidikan Islam, Jakarta: Logos.

Dewan Redaksi Ensiklopedi Islam. 1994. Ensiklopedi Islam, Jakarta: PT. Ichtiar Baru Van Hoeve.

Gazalba, Sidi. 1989. Mesjid Pusat Ibadat dan Kebudayaan Islam, Jakarta: Pustaka al-Husna.

Hamka. 2002. Sejarah Umat Islam, Singapura: Pustaka Nasional.

al-Hassan, Ahmad Y dan Ronald R. Hill. 1993. Teknologi dalam Sejarah Islam, Edisi terjemahan, Bandung: Mizan.

Ibn Manzūur al-Afriqī al-Mișrī. 2000. Lisān al-'Arab, Beirūt: Dār al-Ṣādir.

Keluarga Mahasiswa Aceh (KMA) Cairo. 1995. Panduan Ke Mesir dan alAzhar, Cairo: tp.

Keluarga Mahasiswa Banten (KMB) Cairo. 2010. Serpihan Sejarah Mesir dan Kontribusi Al-Azhar, Mesir: Ahsanta.

Madjid, Nurcholis. 2000. Islam Agama Peradaban, Jakarta, Paramadina, 2000.

Nata, Abudin. 2004. Sejarah Pendidikan Islam: Pada Periode Klasik dan Pertengahan, Jakarta: PT Raja Grafindo Persada.

Shihab, Muhammad Quraish. 2011. Membumikan al-Qur'an Jilid 2, Memfungsikan Wahyu dalam Kehidupan, Jakarta: Lentera Hati.

Su'ud, Muhammad Abdul 'Azim. 2001. Kitab al-Jumhuriyyah al-Azhar wa al-Syuyukh, Mesir: Jumhuriyyah. 